\title{
Taxonomic Dimensions for Studying Situational Method Development
}

\author{
Mehmet N. Aydin ${ }^{1}$, Frank Harmsen ${ }^{2}$ and Jos van Hillegersberg ${ }^{1}$ \\ 1 University of Twente, Department of Information Systems and Change \\ Management. P. O. Box 217, 7500 AE, Enschede, The Netherlands, \\ \{m.n.aydin, j.vanhillegersberg\}@utwente.nl \\ 2 Cap Gemini, Practice Manager Technology Advisory Services, The \\ Netherlands, frank.harmsen@capgemini.nl
}

\begin{abstract}
This paper is concerned with fragmented literature on situational method development, which is one of fundamental topics related to information systems development (ISD) methods. As the topic has attracted many scholars from various and possibly complementary schools of thought, different interpretations and understandings of key notions related to method development are present. In this paper, we regard such understandings as both challenges and opportunities for studying this topic. Upon the extensive review of relevant research, this paper shows how this literature fragmentation has resulted in and what needs to be done to make sense of the various understandings for studying situational ISD methods. For the latter, we propose the use of a number of taxonomic dimensions. We argue that these dimensions can help to ease the conduct of literature review and to position disparate research endeavors concerning situational method development properly. In particular, we discuss three basic studies to demonstrate how the taxonomic dimensions can be useful in studying the subject matter.
\end{abstract}

\section{Introduction}

IS development (ISD) methods have been of interest to IS scholars and practitioners for a long time since they are essential to structuring method users' thinking and actions in projects and achievement of desired information systems. Among other topics, there is a specific subject, which we call method development, addressing all kinds of problems, issues, and solutions with ISD methods. This particular subject 
has a long tradition in several schools of thought. Over the last decades, academics have been urged to investigate the effectiveness of methods as they are not used in practice as prescribed. This research is concerned with fragmented literature for studying method development (MD) and situational method development (SMD) in particular, with a focused research endeavor aiming at studying adaptation of a method to a project situation.

The problem, as perceived and addressed in this paper, is a fragmented body of knowledge (literature) on MD and SMD, which has accumulated significantly over the last two decades. By fragmented literature we mean to say that various research schools of thought do exist, but are disparate and utilization of the existing studies from these schools is lacking. We believe that this fragmentation in turn hinders the advances in the intellectual development on studying method development. Our goal in this paper is two fold. First, it is to bring up this issue and make academics aware of it. Second, it is to propose a means for making sense of literature fragmentation and to draw a generic picture where the academic endeavors are heading.

\section{Review Studies Concerning Method Development}

\subsection{Existing Review Studies and Approaches for MD}

Let us first discuss the concepts of method development (MD) and situational method development (SMD). MD is a subject matter concerning the way through which method stakeholders (such as method experts, project managers and other method users) develop a method in a specific context. Technically, this 'way' can be considered as a mental activity by which method stakeholders analyze [1], adapt and assemble [2] [3] appropriate means to support ways of thinking and actions for ISD projects. SMD is a sub-subject of method development and refers to this adaptation process of method development. It is this process or ability through which (human and non-human) agents determine a system development approach for a specific project situation through responsive changes in, and dynamic interplays between, contexts, intentions, and method fragments [4]. SMD especially employs the input of the analysis and provides the output for the assembly, rather than focuses on method analysis or assembly of method fragments per se. The key issue of situational method development is not exclusive focus on the analysis or the assembly, it is how method fragments, context, and method stakeholders are adapted to each other in a project situation. Thus, what lies at heart of SME is method adaptation [4].

Kumar and Welke [5], and Van Slooten [6] have provided classifications of the approaches to method development. They argue that the "method engineering approach" in Kumar and Welke's terminology and the "situated method engineering" in Van Slooten's terminology are promising approaches for method development. Additionally, Harmsen's [7] and Tolvanen's [8] classifications are specifically for SMD. Harmsen et al. [9] positions various approaches in what they call a "situational method spectrum". As the most flexible or most radical approach to achieve effective method, he proposes an approach, which is central to his thesis and called 
"situational method engineering". Tolvanen's [8] classification uses criteria applied to achieve the methodical requirements of ISD.

Two review studies are worth to mention as they show how MD literature has evolved. One is about the progress of information systems development (ISD) research [10] and the other is concerned with method engineering (ME) research [11]. The progress of ISD research over the past 15 years is referred in terms of the early methodical era (until 1988), the methodical era (until 1995), and the era of method assessment. It is argued that at the end of the methodical era, researchers studying ISD methods questioned and 'listened to' what the field really needed, how practitioners felt about methods, and how they dealt with ISD from a method use perspective. Thus, as they claim, the relevance of exposed methods to practice has been undervalued and not studied thoroughly until 1995. The other review draws a picture of what method engineering research has focused up until 1996 [11]. They claim that most of the studies focus on the technical context (which is about how to efficiently process and store data or sign related concerning method development) and the language context (which concerns different topics such as metamodelling formalisms [12], integration of methods, evaluation of methods, and representational paradigms of ME languages (i.e., supporting a multiparadigmatic representational metamodelling environment- e.g., metaEdit+ and metaCASE [13]). They urge the researchers in the method engineering field to study the organisational context (which concerns human activities, interactions, etc) [14] and actual use methods, tools in fields.

The review studies summarized above provide limited "sense making" (that is, each discusses the subject matter from its own perspective) about the classification of relevant research. The articulations are partial in that they are limited to their schools of thought. They also lack focus on understanding what accounts for situational method development. There is a need for a classification of studies broader on incorporating ideas on method development in various domains. To do this, we visit not only ME and ISD literature, but IS implementation literature that provides insights into the course of implementing (situational) method in an empirical setting.

\subsection{Classification of (Situational) Method Development Related Studies}

At a high level, we distinguish three research domains (the ISD research, Method Engineering, and Implementation research domain (see table 1)) that contribute to an understanding of (situated) method development. The ISD and ME research domains provide insights into the way (situated) method development takes places (that is, a model or process describing how to arrive at a situated method). The ISD and Implementation research domains study the content of such a way (including characteristics and/or elements used in this process).

Having stated the contributions of the three research domains, we examine each domain by using certain elements of the codification schema. The research domains differ in terms of motives, the phenomenon of interest, the label or metaphor used, and associated researchers. 
ISD Research. The main motives in ISD research are to improve IS and ISD, and to reveal and resolve issues concerning them. The ISD research includes two kinds of research focusing on IS, ISD, and ISD method: the variance and process research. The variance research (e.g., [10 15]) aims to build and/or test a model by which cause-effect relationships among dependent, independent, and mediating factors essential to the subject matter are studied. In contrast, the process strategy $[16,17$, $18,19]$ is used to study the phenomenon as a process, a number of events, actions, or episodes that occur in an actual setting where the phenomenon is realized and observed.

The ISD research domain employs ideas and theories from sociology, economics, psychology, and system sciences. One of the earliest uses of this model for determining Management Information Systems design approaches is in [21]. Having stated an overview of this research domain, we posit that their contribution to the theoretical basis of our research may be summarized as follows. The ISD research literature provides: (1) insights into what problems of methods should be targeted in (situated) method development, (2) insights into the functioning, use of method and in work practice, (3) alternative ways of characterizing a target work system, (4) alternative ways of characterizing a method, and (5) alternative ways of selecting the elements of a method.

Method Engineering Research. Under this research domain, we distinguish the following sub- domains: Software Engineering, Requirements Engineering, and SME. Even though the object of interest of these sub-research domains varies with respect to the scope of method under investigation, they often provide procedures for the selection, assembly of components of a method. We briefly discuss the three subresearch streams, but it should be noted that SME is different in that the research efforts are directed to customization of a method to better suit a project situation. Often in this research stream, constituents of method are specified with a certain degree of formality to achieve unambiguous descriptions of the constituents (see e.g., [7], [22]).

Recently, in the Software Engineering ( $S E$ ) research sub-domain, number of methods has been promoted as the solution to the long-standing problem of the socalled conventional software development methods characterized as complex, rigid to change for different project types, technology oriented, and inappropriate for post modern forms of organisations whose distinctive character was adaptable to continual change [23]. The reaction of software engineers and associated researchers [24] has been presented as a manifesto for agile software development. The 'new' methods have been described as 'agile' methods in that they adopt lightweight development processes based on iterative and incremental development, active user involvement, prioritized requirements, etc. [25]. Software engineering literature pays more attention to the stage of application construction and selection of elements of development process by applying techniques in a pragmatic manner. For instance, CMMI (Capability Maturity Model Integration) is used as a model to standardize and measure maturity of the practices for software development. Among a number of key process areas, software product engineering (SPE) indicates the need of tailoring a method. For this purpose, a matrix is often used to match project characteristics to the standardized elements of a software development process [26, 27]. 


\begin{tabular}{|c|c|c|c|c|c|c|}
\hline 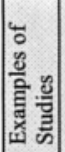 & $\frac{\Xi}{\varrho}$ & $\begin{array}{l}\infty \\
\simeq \\
\stackrel{\infty}{0} \bar{\infty}\end{array}$ & 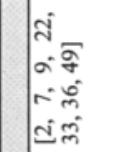 & 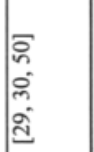 & 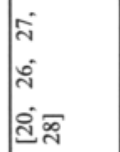 & 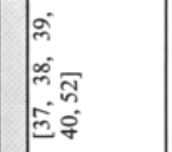 \\
\hline 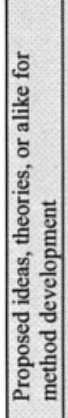 & 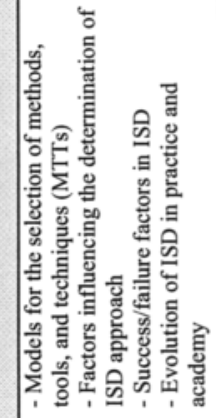 & 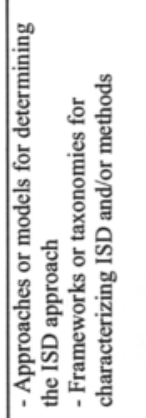 & 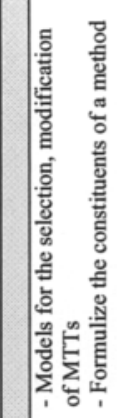 & 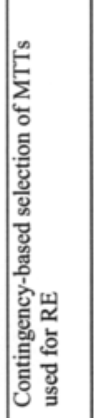 & 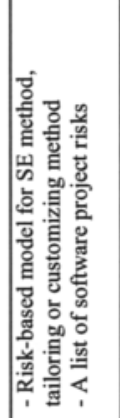 & 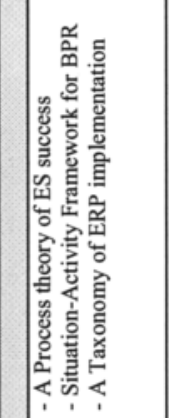 \\
\hline 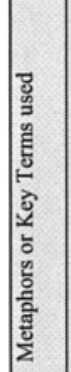 & 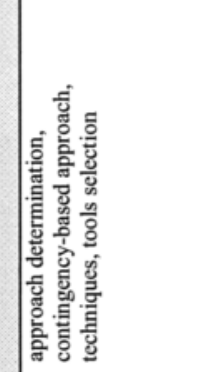 & 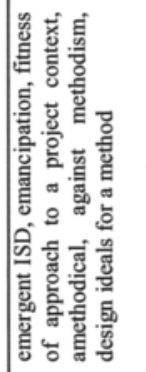 & 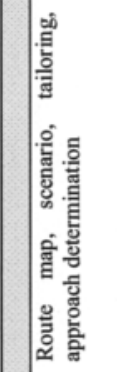 & 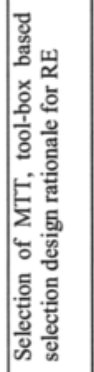 & 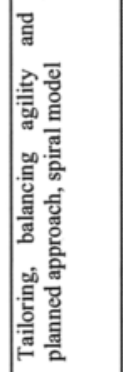 & 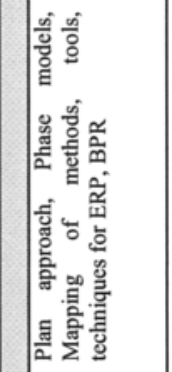 \\
\hline 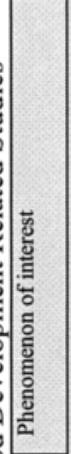 & 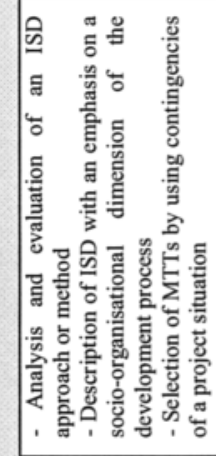 & 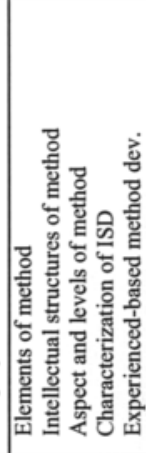 & 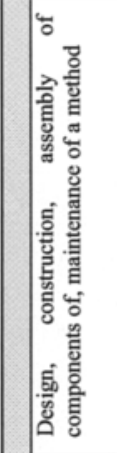 & 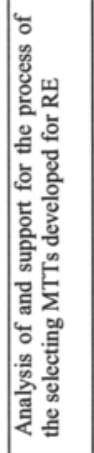 & 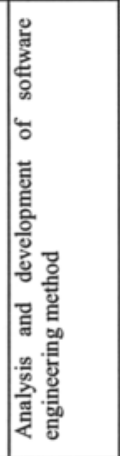 & 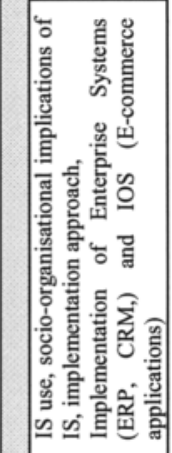 \\
\hline$\sum_{0}^{\circ}$ & 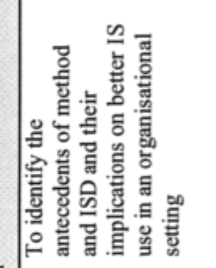 & 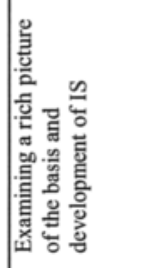 & 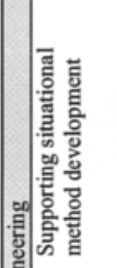 & 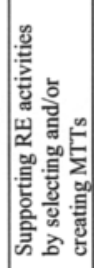 & 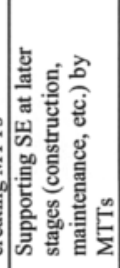 & 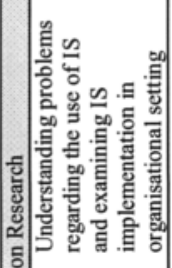 \\
\hline 危 & 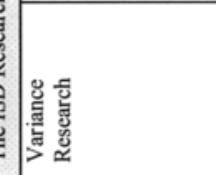 & 怤 & 駋|山 & 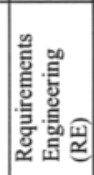 & 惫 & 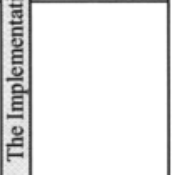 \\
\hline
\end{tabular}


Another example cited is an experience-based approach to method development by which method use-experiences concerning development processes and associated elements such as activities, roles, and deliverables are collected, stored, maintained, and distributed. To facilitate the choice of the appropriate method elements by developers, a case-based reasoning technique is often used through which characteristics of the situation realized are linked to the applied process model and its constituents [28].

The Requirements Engineering ( $R E$ ) research sub-domain has produced many methodical means for major requirements engineering activities such as requirements elicitation, analysis, triage, specification, and verification. Two orientations are seen with regard to method development: the way to support the requirements engineering process along with the design process and the way to select, engineer tools as part of a method. For the requirements engineering process, researchers aim to capture the design rationale and provide the systems developer and project manager with potential benefits in understanding and monitoring the RE process [29]. Several models and support environments (e.g., REMAP: Representation and Maintenance of Process knowledge) are proposed for capturing and supporting design decisions [30]. Rossi et al. [31] adopt REMAP for method rationale in method engineering. For selecting and engineering tools as part of the method, [21] points out the need for developing strategies for information requirements.

The Situational Method Engineering (SME) research sub-domain plays a central role in this work; it provides accounts, approaches, and models for studying method adaptation. The proposed research approaches are of primary importance to this work and called alternately situated method engineering [32], situational method engineering [14], context-specific method engineering [22], and incremental method engineering [13], method configuration [23]; roadmap-driven approaches [33, 34]. In the literature there are a few known accounts that these efforts have been fully utilized [35] and this challenges the applicability of the proposed procedures, models, instruments, and support means concerning method development. This limitation is mentioned in both the ISD (e.g., [35]) and ME literature (e.g., [36]).

Implementation Research. This particular literature (see, exemplary studies [38, 39]) refers to those studies that examine method development in particular domains for certain application types. We use the term implementation because studies in this research domain consider applications as ready-made solutions and often focus on later stages of ISD (e.g., modifications and installation). The level of analysis is limited to a general description of phases, stages, key activities, and tools used in implementation.

We identify a number of sub-research areas that provide relevant studies usually related to enterprise systems implementations, IT-enabled business process (re)engineering, and inter-organisational systems implementation. With regard to method development, the implementation research focuses on risk and success factors of implementation projects and relates them to 'implementation approach' or 'implementation strategy' which is a high level description of the way in which implementation is carried out. Considering an implementation project as technology 
adoption appears to be the dominant view in studying implementation projects. Taxonomies of implementation approaches are provided based on these theories, (see, for instance, [37]). In fact, these phase models or taxonomies (see, e.g., [38, 39]) provide implementation strategies (e.g., big-bang, evolutionary) concerning the development process and essential activities for ISD where the focus is on organisational change-related activities. There are few studies in this domain that specifically examine method development in the context of enterprise systems implementation (especially in relation to enterprise resources planning applications).

This classification of relevant studies and their review indicate that:

- ISD literature (e.g., $[10,15,16])$ provides a partial examination of situational method development as both process and content wise. Most of the proposed models of SME adopt a contingency-based approach which appears to fall short in detailing situated method development.

- ME literature (e.g., $[2,7,9,22,33])$ provides an elaborate examination of situational method development as process wise. A few models proposed for situational method development are actually adopted or extended by most of the studies in the ME research domain.

- Implementation literature (e.g., $[37,38,39]$ ) provides a partial examination of situational method development as content-wise. Most of the proposed models of method development adopt a contingency-based approach.

\section{Manifestation of Taxonomic Dimensions for Studying Situational Method Development}

In this section we propose what we call taxonomic dimensions, which allow to position situational method development related studies (Table 2). The proposed dimensions are induced from those studies which are concerned about comparison of accounts, models for SME $[7,8,14,23]$. We use taxonomic dimensions to critically examine three studies ([2], [7], and [41]), which are considered as prevailing models. The three studies are chosen because: they are found to be the most relevant studies for our purpose (illustrating the usefulness of the proposed dimensions) and they provide underpinnings of SME in terms of basics models.

The first dimension (level of abstraction) has already been mentioned in method engineering. Harmsen [7] introduces three levels of the method engineering hierarchy each of which contains different method knowledge. These levels are: classes of method concepts are described at the method engineering (ME) level, instances of the concepts at the ME level are examined at the ISD method (ISDM) level, and the third level is the information system development (ISD) level at which the actual method fragments of an IS project are located. Notice that the IS situation in which actual business activities are performed is not included in the hierarchy. Most of the IS method engineering studies stay at the ME and ISDM levels, while studies in ISD research and implementation research stay mostly at the ISD level, only few stay at the ISDM level.

The second dimension concerns types of method knowledge [8] in relation with typology of method aspects or components as described in [51]. The shell model on 
method knowledge has six types of method knowledge: conceptual structure including the fundamental concepts of a method and their interrelations; notation with which modelling techniques can be represented; process which indicates how models are created, adopted, and used; participation and roles; development objectives and decisions concerning design choices; and finally assumption and values embedded in a method. For this work, method knowledge concerning development objectives and decisions is central to the examination of situational method development. Related to this dimension, one might consider the level of details or granularity level (fine or coarse grained, see [7]) and degree of formulization via modelling techniques for each type of knowledge.

Table 2. Taxonomic Dimensions for Studying Situational ISD Method

\begin{tabular}{|l|l|}
\hline Taxonomic Dimensions & Operationalisation \\
\hline Level of Abstraction & Method Engineering Hierarchy [7]: Method \\
& Engineering Level, IS Development Method Level, IS \\
& Development Level \\
\hline Knowledge Types & The Shell Model [8]: Conceptual Structure, Notation, \\
& Process, Participation and Roles, Development \\
& Objectives and Decisions, Assumptions and Values \\
\hline Adaptation Situation & Project Specific, Project Independent [4] \\
\hline Aspects of a Situational Method & The Philosophy, The Framework, The Techniques [43] \\
\hline Adaptation Stage & Pre- or Early Stage, Later Stage, Final or Post-Stage \\
\hline Decision Support Aspect & Descriptive, Prescriptive, Normative [42] \\
\hline
\end{tabular}

In addition to these two dimensions, we suggest four additional taxonomic dimensions specifically for situational method development: types of the situation in which adaptation takes place, aspects of a method, adaptation stage, and decisionmaking and support orientation on situational method development. The last dimension is particularly essential for situational method development as it relates to possible viewpoints of decision-making and support on situational method development.

The third dimension, adaptation situation, has two generic variants: projectindependent and project-specific method adaptation. Project-independent refers to the situation in which some predefined situations are taken for granted and for which some contextual attributes are used as a priori knowledge (e.g., types of applications, types of problem situation, target domain characteristics, or other typical project characteristics such as size of project, degree of time pressure) [43]. The latter refers to the consideration of method adaptation in an actual ISD project where the knowledge used for method adaptation is situational in the course of the project rather than based on a priori knowledge. Mirbel and Ralyté [34] propose a typology of (generic model for) various processes and strategies for this kind of adaptation. While this work concerns both types of situations, in the following section we especially focus on those studies examining project-specific method adaptation.

Consider the fourth and fifth dimensions, the aspects of a method along with granularity level and the development level of an IS. For the first, we distinguish three essential aspects at a high level: the philosophy, the framework and essential techniques, and we adopt Wijers' way of thinking, modelling, working, supporting, 
and controlling [44]. The philosophy aspect is akin to the way of thinking, the essential techniques aspect is more or less similar to the way of controlling and supporting, and the other ways of Wijers [44] are subsumed in the framework aspect.

The fifth dimension indicates the positioning of situational method development on the ISD timeline. Several notions or terms are used to logically split the timeline or workflow of ISD. For instance, Harmsen [7] used the term 'stages of ISD' referring to decreasing level of abstraction (e.g., business modelling, functional design, technical design, and implementation) or increasing level of detail (e.g., global analysis, detailed analysis, global design, detail design). Van Slooten [2] uses 'the levels' as he adopts Zachman's framework [46] (e.g., scope, object system and analysis and design level (OSAD), information system analysis and design (ISAD) level and so on). The implementation literature (e.g., [39]) uses several stages or phases. Given the multiplicity of the terms, we prefer to use the timeline notion in terms of beginning, earlier, during, and later time in ISD.

The final dimension is decision-making and support orientation on situational method development. We address three basic views on decision-making and decision support: normative, descriptive, and prescriptive. These are cited as key orientations pertaining to the decision-making and support model (e.g., [42]). We closely examine these three orientations later and outline them now to see how method adaptation can be analysed from a decision-making and support point of view. The normative view is mainly concerned with the question "How should people ideally make decisions?"; the descriptive view focuses on "How and why people make decisions" whereas the prescriptive view addresses "How can we help people make better (not necessarily ideal) decisions while still taking human cognitive limitations into account".

\subsection{Examining Prevailing Models for Situational Method Development}

In this section we examine each of the three models based on the proposed taxonomic dimensions (see table 2, which summarizes the examination). While articulating these dimensions we show how to characterize and in turn compare them.

\section{"Situated Method Engineering" and Configuration Procedure for a Scenario}

Van Slooten introduces "Situated Method Engineering", a particular model of situation-specific approach to method development. Four notions (project context, configuration process, project performance, and method engineering information systems consisting of formalized rules and a method base that includes method and route map fragments) are suggested to describe the process of SME. The configuration procedure, acknowledged as the heart of method engineering, that includes other notions such as (method) fragments, route maps, intermediate variables (aspects, levels, constraint, and development strategy) scenarios, and their relations.

Positioning Along With Taxonomic Dimensions. With a concise and in-depth presentation of SME, we are ready to explicate the taxonomic dimensions. Notice that Van Slooten [2] has not used or mentioned the proposed taxonomic dimensions 
in his work. Given the fact that he was one of few researchers investigating the idea of situation-specific approach to method adaptation in the $1990 \mathrm{~s}$, his works can be seen as explorations of this idea in an organisational setting and the introduction of a new model, new notions, and new concepts without always providing their clear cut definitions as his findings have been conceptualized and perpetuated during the course of an investigation that goes back to 1987 [47]. Nevertheless, we are now able to apply the taxonomic dimensions to better understand his endeavors.

Table 3. Applying the taxonomic dimensions to the three models proposed for SME

\begin{tabular}{|c|c|c|c|}
\hline $\begin{array}{l}\text { Taxonomic } \\
\text { dimensions }\end{array}$ & $\begin{array}{l}\text { The Configuration } \\
\text { Procedure for a Scenario } \\
{[2]}\end{array}$ & $\begin{array}{l}\text { The S3 (Situation } \\
\text { Scenario and Success) } \\
\text { Model [7] }\end{array}$ & $\begin{array}{l}\text { A Social Process for } \\
\text { Method Fragment } \\
\text { Adaptation [41] }\end{array}$ \\
\hline $\begin{array}{l}\text { Level of } \\
\text { Abstraction }\end{array}$ & $\begin{array}{l}\text { The ISD Method and ISD } \\
\text { levels }\end{array}$ & $\begin{array}{l}\text { The ME, ISD Method } \\
\text { levels }\end{array}$ & $\begin{array}{l}\text { The ISD Method and } \\
\text { ISD levels }\end{array}$ \\
\hline $\begin{array}{l}\text { Knowledge } \\
\text { Types }\end{array}$ & $\begin{array}{l}\text { Mainly development } \\
\text { objectives and decisions }\end{array}$ & $\begin{array}{l}\text { All types, except } \\
\text { assumptions and values }\end{array}$ & $\begin{array}{l}\text { Mainly conceptual } \\
\text { structure, notation }\end{array}$ \\
\hline $\begin{array}{l}\text { Adaptation } \\
\text { Situation }\end{array}$ & $\begin{array}{l}\text { Project independent and } \\
\text { to a certain extent project } \\
\text { specific }\end{array}$ & $\begin{array}{l}\text { Project independent and } \\
\text { to a certain extent } \\
\text { project specific }\end{array}$ & Project specific \\
\hline $\begin{array}{l}\text { Aspects of a } \\
\text { Situational } \\
\text { Method }\end{array}$ & $\begin{array}{l}\text { The framework and } \\
\text { techniques }\end{array}$ & $\begin{array}{l}\text { The framework and } \\
\text { techniques }\end{array}$ & The framework \\
\hline Adaptation Stage & Mainly early stage & Mainly early stage & $\begin{array}{l}\text { Not specifically } \\
\text { mentioned }\end{array}$ \\
\hline $\begin{array}{l}\text { Decision Support } \\
\text { Aspect }\end{array}$ & Mainly prescriptive & Mainly prescriptive & Descriptive \\
\hline
\end{tabular}

With regard to the level of abstraction, the SME proposed appears to stay at the ISDM level for which he provides a 'configuration procedure' model and at the ISD level for which he has described how (route map or method) fragments have been used in an actual project context. With regard to the type of method knowledge, we contend that the proposed SME emphasizes the method knowledge type pertaining to the development objectives and decisions concerning design choices of a situational method. With regard to the adaptation situation, it suggests the use of a configuration process in the course of the project situation, but appears that project execution is a black box for method adaptation: only the output of the black box is used to feed 'method base' and 'project characterization'. The SME proposed employs on the one hand a priori knowledge (known or foreseen contingencies, project characteristics) about the project that implies project-independent method adaptation, while on the other hand it acknowledges the unprecedented project situation and includes a feedback mechanism but is not fully operationalized to accommodate method adaptation in the progress of ISD. With regard to the aspect of a method, the SME proposed supports all aspects except the way of thinking, along with a variety of fragments. With regard to the adaptation stage, it is clearly proposed for the beginning or earlier time. With regard to the final dimension, we contend that the decision-making model behind the configuration procedure is prescriptive, but the decision-making model behind the framework is descriptive as mentioned in [2]. The 
SME proposed does not exclusively focus on what/how or by whom decision support is or can be provided for situational method development.

\section{Situational Method Engineering and the S3 -Situation, Scenario and Success- Model}

Harmsen and his colleagues [7, 9] have worked on the idea of the situationspecific approach to method adaptation by adopting a slightly different orientation on the subject. Most of their work seems to provide clear-cut definitions of the models, notions, and concepts suggested for what they call "Situational Method Engineering" (SME), referring to the research discipline focus on development of situational methods. In Harmsen [7] basic concepts of SME are described. Among other things, his works include an ontology for product fragments and a process classification system to anchor fragments with their semantics, Method Engineering Language (MEL) to enable method fragment representation, the SME process indicating the necessary steps needed to achieve situational method, and the $\mathrm{S}^{3}$ model relating the three key notions- Situation, Scenario, and Success, which is proposed for the selection and assembly of method fragments

Positioning Along With Taxonomic Dimensions. SME is one of the first attempts to provide a full-fledged description of the basic concepts needed for the design and construction of a situational method. Harmsen and his colleagues' endeavours have often been cited as a significant attempt for formalization of the basic concepts required for a situational method or as a limited view on the way a method adaptation can be realized (see, for instance, [22], [33], [36]). With regard to the level of abstraction, SME stays at the ME level where it provides descriptions of basic concepts and their relationships for a situational method. With regard to knowledge type, SME does not limit itself to any particular type of method knowledge, but appears to employ a special conceptual structure and notation pertaining method knowledge probably due to the need for a degree of formalization of concepts and their relationships often expected by the IS ME community. The level of detail preferred is fine grained in terms of semantics of method fragments in SME. With regard to the adaptation situation, situated and situational method engineering have some similarities. Nevertheless, this approach puts more attention on project-specific adaptation as it acknowledges changes in project situation in the later stages of ISD. Given the characteristics mentioned, the adaptation stage is clearly proposed for the beginning or earlier time of ISD. Finally, SME includes procedures for method adaptation with a reservation that human and/or inanimate agents have some freedom to adhere to these procedures with regard to decisionmaking and support. In general, however, SME opts for a prescriptive view and even uses some normative techniques like cluster analysis on method adaptation. We believe that decision-making support for situational method development is not the central focus of these suggested CAME tools.

\section{A Social Process for Method Fragment Adaptation}

Baskerville and Stage put more emphasis on the emergent aspect of ISD and argue that much of the literature on method development is normative, conceptual and that empirical work is lacking [41]. One of the central notions in their work is "work practice'. This refers to the way in which a concrete development process is actually 
conducted in practice. They show that this notion may be best understood together with two additional concepts: situation and constraint. Though they do not provide clear definitions of these terms, they discuss how the concepts are related. They assert that "The conditions and work practice influence the situations that occur, the situations may change conditions and work practices, and work practices may filter the influence of conditions on the situations that occur (p. 15)". Their work focuses on the way work practice is supported and the selection of a method fragment. Such a selection process is seen as a sociological process in their work. They acknowledge that method engineering endeavours are directed towards such a selection process and have some limitations on the way method adaptation is treated.

Positioning Along With Taxonomic Dimensions. Baskerville and Stage's [41] comment on the limitations of 'method engineering' on method adaptation appears in R. Baskerville's earlier work. For instance, Baskerville [48] already mentions the need to look into work practice, which corresponds to the level of ISD in method engineering hierarchy, to identify ISD conflicts and fit these conflicts to structural artefacts at the third level of abstraction which corresponds to the ISD method engineering hierarchy. So, with regard to level of abstraction, their work concerns method adaptation at the ISD method and ISD levels. With regard to the types of method knowledge, their framework does not emphasize certain types, but examples in their work are related to conceptual structure and notational types of method knowledge. The degree of formality used in their illustrative case is coarse grained and expressed in terms of narratives. The proposed process model aims for a projectspecific method adaptation and does not focus on particular aspects of method. Even though there is no clear emphasis on the timeline dimension of method adaptation in their work, from the illustrative case study it appears more attention is given to the earlier time of ISD. Concerning the decision-making and support dimension, the object of interest in terms of method stakeholders is extended to a broader audience including designers, users, programmers, method engineers, and other people involved in the project and/or the target IS domain. Their work does not mention any decision-making support in method adaptation and the decision rational behind their model reflects a descriptive view on method adaptation.

\section{Concluding Remarks}

This research is aimed to bring up the issue of fragmented literature on method development in general and situational method development in particular. We show three basic research domains studying method development, as each domain its own motives, research concerns, research approaches and methods. We argue that the academics in these domains do rarely refer to cross domains. Their endeavors are diverging rather than overlapping. As we regard these domains as complementary rather than competing, they need to be utilized. For instance, one can study how these domains understand and adopt certain notions (situation, context, agency, method fragment) for their theoretical underpinnings. We suspect that such notions have been incorporated with different interpretations in their domains. 
To make sense of the fragment literature, we propose taxonomic dimensions for studying situational method development. One might argue completeness of the taxonomic dimensions, but in this work we consider them as a means to characterize and compare models of SME. That is, one can evaluate these dimensions in terms of their relevance to the subject examined and so the dimensions can be extended. To demonstrate how to use these dimensions we have examined three basic studies and showed that they are providing three alternative approaches to studying the subject matter. For instance, by employing the decision support dimension we point out that the models of $[2,7]$ are aimed to support SME practice in a prescriptive manner. On the other hand, the model of [41] is directed towards identifying and understanding of the SME practice in a project situation (that is, a descriptive view on the decision support dimension). In a similar way, the other proposed dimensions can help one to better understand the existing accounts, models and alike related to method development. In particular we contend that fragmented literature can be seen as an opportunity for utilizing complementary views on and enhancing the understanding of method development. It is this understanding that can help academics to know where their research stands and where research endeavors are heading towards.

\section{References}

1. N. Jayaratna, Understanding and Evaluating Methodologies (McGraw-Hill, Berkshire, 1994).

2. C. van Slooten, Situated Methods for Systems Development, Doctoral Dissertation, University of Twente (1995).

3. S. Brinkkemper, M. Saeki and F. Harmsen, Assembly Techniques for Method Engineering. CAiSE 1998, 381-400 (1998).

4. M. N. Aydin, F. Harmsen, C. van. Slooten R. A. Stegwee, On the Adaptation of An Agile Information Systems Development Method, Journal of Database Management, Special issue on Agile Analysis, Design, and Implementation, 16(4): 24-40 (2005).

5. Kumar and R. J. Welke, Methodology Engineering: A Proposal for Situation-Specific Methodology Construction. in: Challenges and Strategies for Research in Systems Development Method, edited by W. W. Cotterman, J. A. Senn (John Wiley \& Sons, 1992).

6. C. van Slooten and B. Schoonhoven, Contingent Information Systems Development, Journal of Systems and Software, 33(2) 153-161 (1996).

7. F. Harmsen, Situational Method Engineering (Moret Ernst \& Young Management Consultants, Utrecht, 1997).

8. J. -P. Tolvanen, Incremental Method Engineering with Modeling Tools - Theoretical Principles and Empirical Evidence. Computer Science, Economics and Statistics. ER-Paino Ky, University of Jyväskylä: 301 (1998).

9. F. Harmsen, S. Brinkkemper, and H. Oei, Situational Method Engineering for Information Systems Projects. in: Methods and Associated Tools for Information Systems Life Cycle, edited by T. W. Olle and A. V. Stuart (North-Holland, Amsterdam, 1994) pp.169-194.

10. D. Avison and G. Fitzgerald, Reflections on Information Systems Development 19882002, in: Information Systems Development - Advances in Methodologies, Components, and Management, edited by M. Kirikova et al. (Kluwer Academic Publishers, 2002) pp.111.

11. J. -P. Tolvanen, M. Rossi, and H. Liu, Method Engineering: Current research directions and implications for future research, in: Principles of Method Construction and Tool Support, edited by S. Brinkkemper, K. Lyytinen and R. J. Welke (Chapman \& Hall: 1996). 
12. J. van Hillegersberg and $\mathrm{K}$. Kumar, Using metamodeling to integrate object-oriented analysis, design and programming concepts, Information Systems, 24 (2), 113-129 (1999)

13. S. Kelly, A Matrix Editor for a metaCASE Environment, Information and Software Technology, 36( 6), 361-171 (1994).

14. K. Lyytinen, A Taxonomic Perspective of Information Systems Development: Theoretical Constructs, in: Critical issues in information systems research, edited by R. J. Boland, R. A. Hirschheim (John Wiley \& Sons Ltd., 1987) pp. 3-41.

15. J. Iivari, R. Hirschheim, and H. K. Klein, A Dynamic Framework for Classifying Information Systems Development Methodologies and Approaches, Journal of Management Information Systems, 17(3), 179-218 (2001).

16. A. G. van Offenbeek and P. L. Koopman, Scenarios for system development: matching context and strategy, Behavior \& Information Technology, 15(4), 250-265 (1996).

17. L. D. Introna and E. A. Whitley Against method: Exploring the limits of method, Information Technology \& People, March 10(1), 31-45 (1997).

18. D. R. Truex, R. Baskerville, and J. Travis, Amethodical system development: the deferred meaning of systems development method, Accounting, Management \& Technology, 10,: 53-79 (2000).

19. G. F. Lanzara and L. Mathiassen, Mapping Situations. Information and Management, 8(1): 71-107 (1985).

20. L. Mathiassen, and J. Stage, The Principle of Limited Reduction in Software Design, Information, Technology and People, 6(2) (1992).

21. G. B. Davis, Strategies for Information Requirements Determination, IBM Systems Journal, 20(1), 4-30 (1982).

22. C. Rolland, and N. Prakash, A proposal for context-specific method engineering, in: Principles of Method Construction and Tool Support, edited by S. Brinkkemper, K. Lyytinen and R. J. Welke (Chapman \& Hall: 1996) pp.191-208.

23. F. Karlsson and P.J. Agerfalk, Method Configuration: Adapting to situational characteristics while creating reusable assets, Information and Software Technology, 46(9): 619-633 (2004).

24. Beck, K. et al., Manifesto for Agile Software Development [Online Web Site]. The Agile Alliance. Available WWW: http://agilemanifesto.org/ (2001)

25. P. Abrahamsson, J. Warsta, M. T. Siponen, J. Ronkainen, New Directions on Agile Methods: A Comparative Analysis. ICSE 2003, May 3-10, Portland, Oregon, USA., 244254 (2003).

26. C. Larman, V. R. Basili, Iterative and Incremental Developments: A Brief History, IEEE Computer, 36(6), 47-56 (2003).

27. T. Kaltio and A. Kinnula, Deploying the Defined SW Process, Journal of Software Process: Improvement and Practice, 5(1), 65-83 (2000).

28. S. Henninger and K. Baumgarten, A Case-Based Approach to Tailoring Software Processes. International Conference on Case-Based Reasoning, Vancouver, Canada, 249262 (2001).

29. L. Nguyen and P. A. Swatman, Managing the Requirements Engineering Process. Requirements Engineering Journal, 8, 55-68 (2003).

30. C. Potts and G. Bruns, Recording the reasons for design decisions. the Proceedings of 10th Int. Conf. Software Eng., IEEE Comp. Soc. Press (1998).

31. M. Rossi et al., Method Rationale in Method Engineering. Proceedings of the HICSS-33, Maui, HI, IEEE Computer Society (2000)

32. C. van Slooten, B. Hodes, Characterizing IS development projects, in: Principles of Method Construction and Tool Support, edited by S. Brinkkemper, K. Lyytinen and R. J. Welke (Chapman \& Hall: 1996) pp. 29-44.

33. J. Ralyté, R. Deneckèr, C. Rolland, Towards a Generic Model for Situational Method Engineering. CAiSE 2003, Springer-Verlag Berlin Heidelberg (2003).

34. I. Mirbel and J. Ralyté, Situational Method Engineering: Combining assembly-based and roadmap driven approaches, Requirements Engineering 11(1):58-78 (2006). 
35. R. Hirschheim, H. K. Klein, and K. Lyytinen, Exploring the Intellectual Structures of Information Systems Development: A Social Action Theoretic Analysis. Accounting, Management \& Technology 6(1/2), 1-64 (1996).

36. B. Henderson-Sellers, Method Engineering for OO Systems Development. Communications of the ACM, 46(10), 73-78 (2003).

37. A. Parr, G. Shanks, and P. Darke, Identification of Necessary Factors for Successful Implementation of ERP Systems. New Information Technologies In Organisational Processes - Field Studies And Theoretical Reflections On The Future Of Work, Kluwer Academic Publishers, 99-119 (1999).

38. H. C. Lucas, J. Walton, and M. J. Ginzberg, M. J., Implementing Packaged Software., MIS Quarterly, 12(4) 537-549 (1988).

39. M. L. Markus et al. Learning from Adopters' Experiences with ERP-Successes and Problems, Journal of Information Technology, 15(4) (December) 245-265 (2000)

40. W. J. Kettinger, J. T. C. Teng, and S, Guha, Business Process Change: A Study of Methodologies, Techniques, and Tools, MIS Quarterly, 21(3): 55-80 (1997).

41. R. Baskerville and J. Stage, Accommodating emergent work practices: Ethnographic choice of method fragments. In realigning research and practice: The social and organisational perspectives, Boston, Kluwer Academic Publishers, 11-27 (2001).

42. D. E. Bell, H. Raiffa, and A. Tversky, Descriptive, normative, and prescriptive interactions in decision making, in: Decision making: Descriptive, normative, and prescriptive interactions, edited by Bell, Raiffa, and Tversky (Cambridge University Press, New York, 1988).

43. M. N. Aydin, F. Harmsen, Making a Method Work for a Project Situation, in: the Context of CMM, edited by Oivo and Komi-Sirvio, LNCS: 2559, Springer Verlag Berlin, 158-171 (2002).

44. G. M. Wijers, Modelling Support in Information Systems Development, Delft University of Technology, Delft (1991).

45. M. Leppänen, Conceptual Evaluation of Methods for Engineering Situational ISD Methods, in: Software Process: Improvement and Practice, 11 (5), 539-555 (2006)

46. J. A. Zachman, A Framework for Information Systems Architecture. IBM Systems Journal, 26(3) (1987).

47. C. van Slooten, Systeemontwikkelingsmethoden (In English: Systems Development Methods) Informatie, 4 (1987).

48. R. Baskerville, Structural artifacts in method engineering: the security imperative in: Principles of Method Construction and Tool Support, edited by S. Brinkkemper, K. Lyytinen and R. J. Welke (Chapman \& Hall: 1996) pp. 8-28.

49. I. van de Weerd, S. Brinkkemper, J. Souer, and J. Versendaal,. A Situational method for web-based content management system-applications: Method engineering and validation in practice. Software Process Improvement and Practice, 11:521-538 (2006).

50. T. Tsumaki and T. Tamai. Framework for matching requirements elicitation techniques to project characteristics, Software Process Improvement and Practice, 11, 505-519 (2006).

51. K. Wistrand and F. Karlsson, Method Components - Rationale Revealed. In: A. Persson and J. Stirna (Eds.). CAiSE 2004, LNCS: 189-201 (2004).

52. A. Parr, G. Shanks, and P. Darke, Identification of Necessary Factors for Successful Implementation of ERP Systems. New Information Technologies, in: Organisational Processes - Field Studies and Theoretical Reflections on the Future of Work (Kluwer Academic Publishers, 1999), pp. 99-119. 